\title{
Research on the friction stir welding of Titanium Grade 1
}

\author{
R. Kosturek ${ }^{1, a}$, M. Wachowski ${ }^{1}$, T. Ślęzak ${ }^{1}$, L. Śnieżek ${ }^{1}$, J. Mierzyński $^{1}$, U. Sobczak ${ }^{1}$ \\ ${ }^{1}$ Military University of Technology, Faculty of Mechanical Engineering, 2 gen. W. Urbanowicza str., 00-908 Warsaw, Poland
}

\begin{abstract}
In this research the three different FSW joints of Titanium Grade 1 have been performed by using tool made of W25Re alloy with different welding velocity values. In order to investigate the influence of FSW process on microstructure of joined material the light microscope observations have been performed on the etched samples. It has been reported that significant grain refinement occurs in the stir zone in all analyzed samples. On the other hand, occurrence of weld defects, such as tunneling defect and kissing bond has been noticed. The microhardness analysis of the cross-section of the obtained joints indicates on microhardness increasing in the stir zone by 40-60 HV0,1 compared to the base material. Peak hardness of stir zone in the researched samples has tendency to decrease along with increasing of welding velocity. The strength of obtained joints was designated in the uniaxial tensile tests and confronted with strength of base material. Despite the occurrence of weld defects the established joints efficiency contains in range $92-94 \%$. It has been stated that Young's modulus of Titanium Grade 1 FSW joints is $15-19 \%$ lower in comparison to the base material. At the same time, no significant influence of FSW on the ductility of material were observed.
\end{abstract}

\section{Introduction}

One of the most promising lightweight materials for used in modern engineering are titanium alloys [1,2]. Due to their high specific strength, corrosion resistance and high melting point titanium alloys have a great potential to increase their participation as construction materials in aircraft and aerospace industry [3-5]. One of the problems, which limit their wider use are obstacles concerned with fusion welding process, such as significant workpiece distortion and low quality of joints [6-8]. The technology, which has potential for replacement the fusion welding as the basic technology of joining titanium is the friction stir welding (FSW) $[9,10]$. FSW technique is the solid-state welding process, widely used for joining light alloys, such as aluminum and magnesium alloys. The process of joining is based on friction between workpieces and the rotating tool, which generates heat leading to plasticizing of material to be welded [9,11-13]. The movement of rotating tool along the edges of two workpieces causes mixing of plasticized material, and as the result the creation of joint between them $[9,12]$. Although the joining of aluminum alloys is easy to perform due to relatively low temperature of its plasticization, in case of titanium the higher welding temperature is required $[9,12]$. It can be provided by using more heat-generated welding parameters, which forces the adaptation of welding tool made of material able to work in high temperature environment, having excellent mechanical properties, as well as, outstanding wear resistance [13-15]. For this reason, the materials such as W-La alloys, WC-
Co and polycrystalline cubic boron nitride (PcBN) and are used for the tool material in FSW of titanium alloys $[16,17]$. One of the recent proposed material with excellent wear properties, superior to WC-Co alloys is W25Re alloy [16]. In this investigation the self-designed tool made of tungsten-rhenium alloy (W25Re) has been used to perform the friction stir welding joints of Titanium Grade 1. The properties, as well as, exact geometry of designed tool have been presented in the previous investigation [18]. The main aim of this research is to investigate the possibility of obtaining high-quality joint of titanium grade 1 in FSW process by using tool made of W25Re alloy.

\section{Experimental procedure}

The joints of Titanium Grade 1 plates were successfully obtained using friction stir welding method. Joints were made using $250 \times 1000 \times 3.2 \mathrm{~mm}$ plate samples. The welded plates were held firmly using fixtures to prevent distortion during process. Before welding surfaces of plates were machined in order to negate oxide influence. Welding was performed using a fully-controlled FSW machine ESAB Legio 4UT. Welds were made along the longitudinal direction of the sheet (parallel to the rolling direction of plates). The welding tool used was designed by authors and made of W25Re and equipped in conical smooth pin diameter of 5-6 mm and $3 \mathrm{~mm}$ length. To obtain the joints three sets of welding parameters were used (Table 1). During the FSW,

\footnotetext{
${ }^{a}$ Corresponding author: robert.kosturek@wat.edu.pl
} 
a $2^{\circ}$ tilt, plunge depth of $3 \mathrm{~mm}$ and $20 \mathrm{kN}$ axial force were applied to the FSW tool. Argon shielding gas was used for protection of the stir zone during welding due to high solubility of hydrogen, nitrogen and oxygen in hot titanium, what can lead to brittleness of obtained joints.

Table 1. Samples designation.

\begin{tabular}{|c|c|}
\hline Shortcut & Description \\
\hline Ti-75 & $\begin{array}{l}\text { Tool rotation speed: } 250 \mathrm{rpm} \\
\text { Welding speed: } 75 \mathrm{~mm} / \mathrm{min}\end{array}$ \\
\hline Ti-100 & $\begin{array}{l}\text { Tool rotation speed: } 250 \mathrm{rpm} \\
\text { Welding speed: } 100 \mathrm{~mm} / \mathrm{min}\end{array}$ \\
\hline Ti-200 & $\begin{array}{l}\text { Tool rotation speed: } 250 \mathrm{rpm} \\
\text { Welding speed: } 200 \mathrm{~mm} / \mathrm{min}\end{array}$ \\
\hline
\end{tabular}

The welded joints were sectioned perpendicular to the welding direction where metallurgical examinations and hardness measurements were carried out. In order to investigate the joint microstructure, the samples were examined using light microscope (Olympus LEXT OLS 4100). The samples were mounted in resin, grinded with abrasive paper of $80,320,600,1200$ and 2400 gradations, polished using diamond paste of $1 \mu \mathrm{m}$ gradation and then etched in mixture of mixture of $\mathrm{HF}(5 \mathrm{ml}), \mathrm{HNO}_{3}(5 \mathrm{ml})$ and $\mathrm{H}_{2} \mathrm{O}(70 \mathrm{ml})$ to revel the microstructure of titanium.

The Vickers microhardness measurements of the polished cross sections were taken at near mid-thickness across the welds by applying a load of $0.1 \mathrm{~kg}$. Microhardness distributions were prepared for each sample.

The strength of obtained FSW joints of Ti gr. 1 was assessed during uniaxial tensile tests. The tests were performed using Instron 8802 hydraulic pulsator equipped with extensometer with a gage length of $50 \mathrm{~mm}$. The dog-bone shaped samples had a cuboidal measuring section with dimensions of $30 \times 3$ and length of $75 \mathrm{~mm}$. Tensile tests were carried out according to ISO 6892-1.

\section{Results}

\subsection{Microstructure}

The light microscope observations revealed the microstructure of obtained joints (Fig. 3). In all cases the joints have a microstructure specific for friction stir welded titanium, which consists of stir zone (SZ), thermo-mechanically affected zone (TMAZ) and base material (BM). Independently from the welding velocity the width of the stir zone in all cases is equal to $5.5 \mathrm{~mm}$ at the half of its height. On the other hand, the width of the thermo-mechanically affected zone decreases along with increasing of the welding velocity. It is equal to $2.2 \mathrm{~mm}$, $2 \mathrm{~mm}$ and $1.5 \mathrm{~mm}$ at the half of the joint height for the samples Ti-75, Ti-100 and Ti-200 respectively. Microstructure of the stir zone is characterized by ultrafine equiaxial grains (Fig. 1).

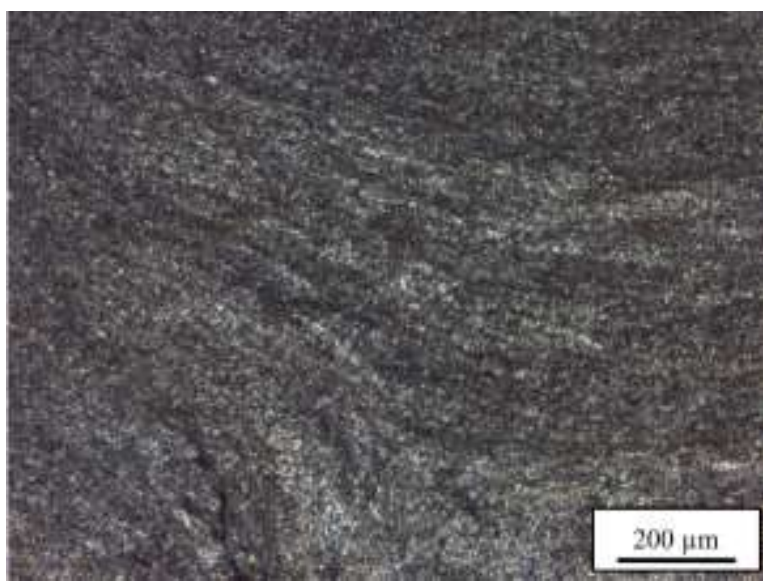

Figure 1. Microstructure of stir zone in Ti-200 sample.

This zone has been formed by direct acting of rotating tool on workpiece material. Severe plastic deformation and high temperature occurring in the stir zone during welding process results in formation of dynamically recrystallized ultrafine grain microstructure with average grain size

of $5 \mu \mathrm{m}$. Between the stir zone and the base material occurs the thermo-mechanically affected zone (TMAZ) (Fig. 2).

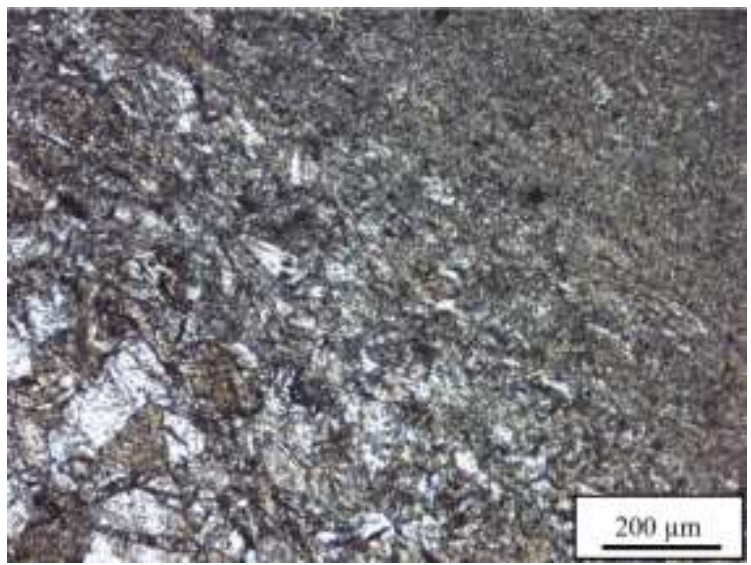

Figure 2. Microstructure of thermo-mechanically affected zone in Ti-200 sample.

TMAZ microstructure is characterized by thinner grains than base material, with visible deformation texture. In this area, the material has been subjected to the plastic deformation, as well as, has been influenced by high temperature, but not in sufficient way to cause the dynamic recrystallization of the microstructure. It has been noticed that the number of twin boundaries in this zone increased compared to the base material. The microstructure of TMAZ changes from the fine, fragmented grains to the grains elongated in the direction of material flow, and finally reaches the partially deformed grains zone. The obtained joint has two types of FSW defects: the tunneling defect, as well as, the kissing bond. The performed microhardness analysis allowed to estimate the influence of FSW process on hardening of material (Fig. 5).

\subsection{Mechanical properties}


Three tests were conducted for the base material and each prepared FSW joint. Obtained results are presented in Fig. 4 in the form of stress-strain curves. In table 2 are showed the average values of Young's modulus E, yield strength $\mathrm{R}_{0,2}$, ultimate strength $\mathrm{R}_{\mathrm{m}}$ and elongation A.
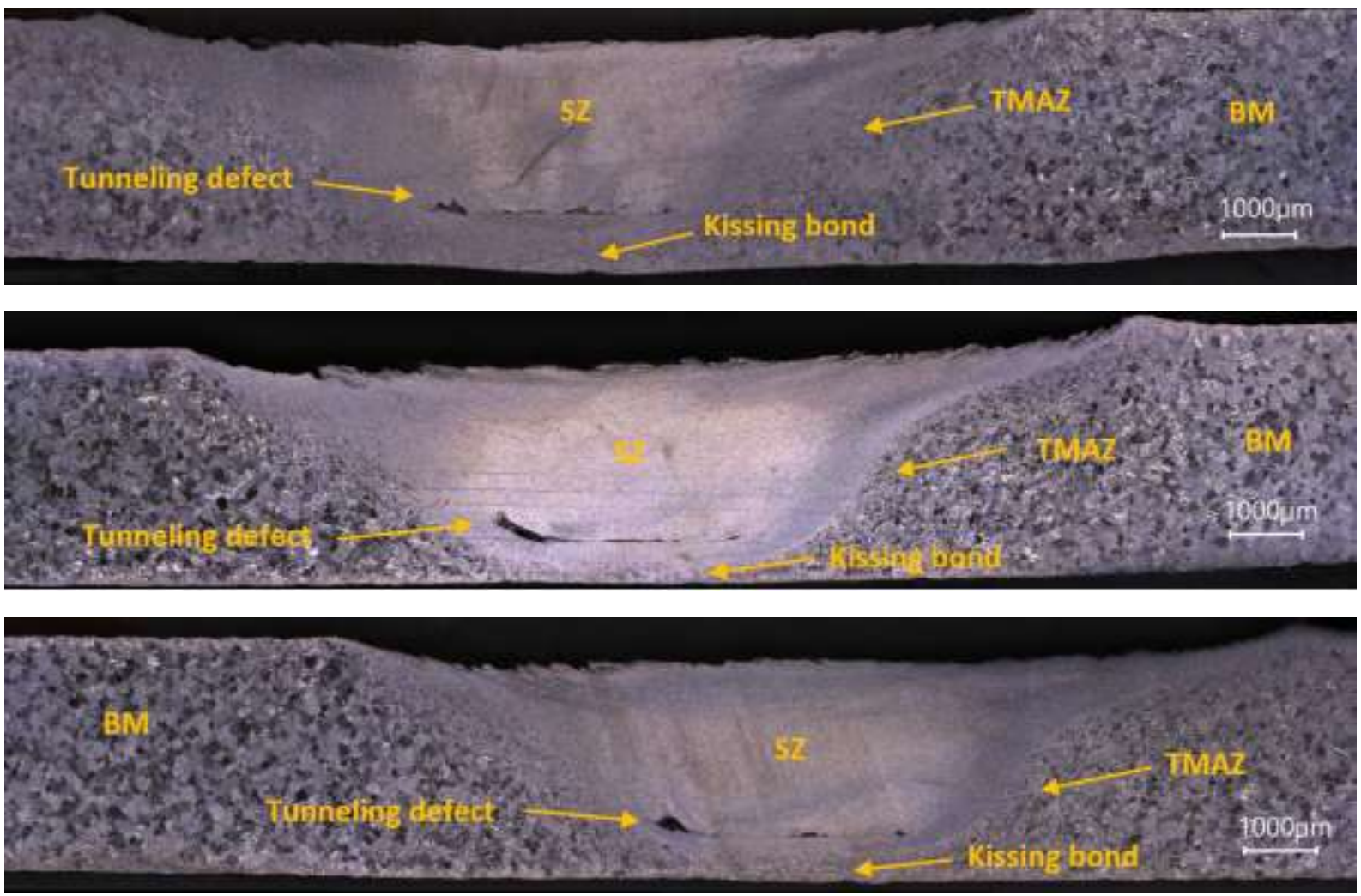

Figure 3. Microstructure of the welds (a) Ti-75 sample (b) Ti-100 sample (c) Ti-200 sample.

a)

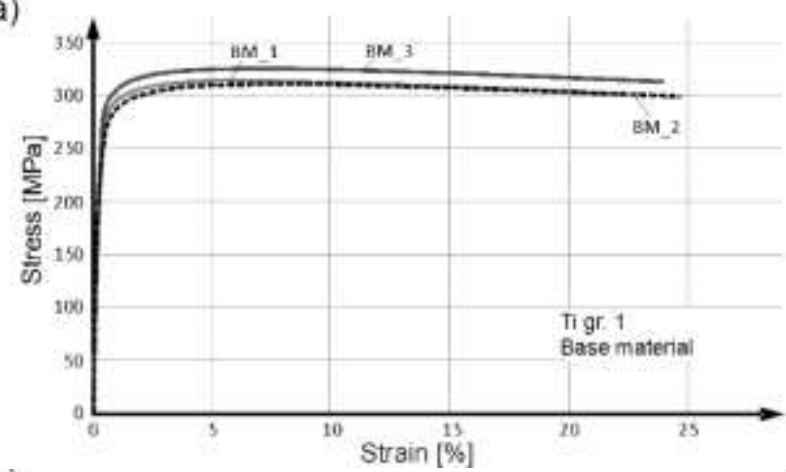

b)

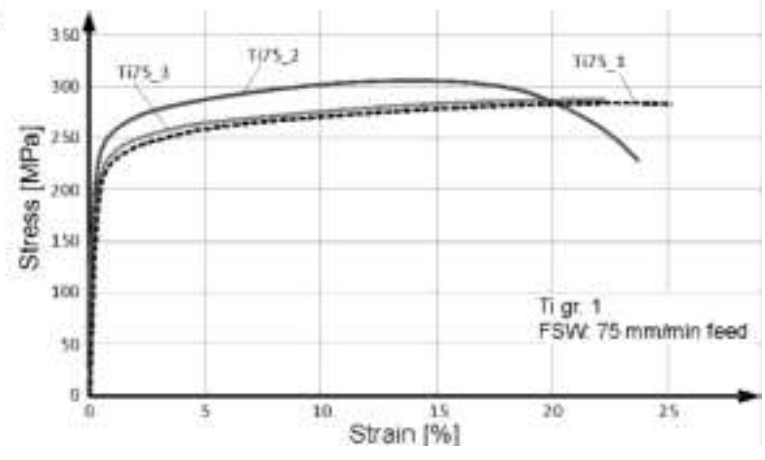

c)

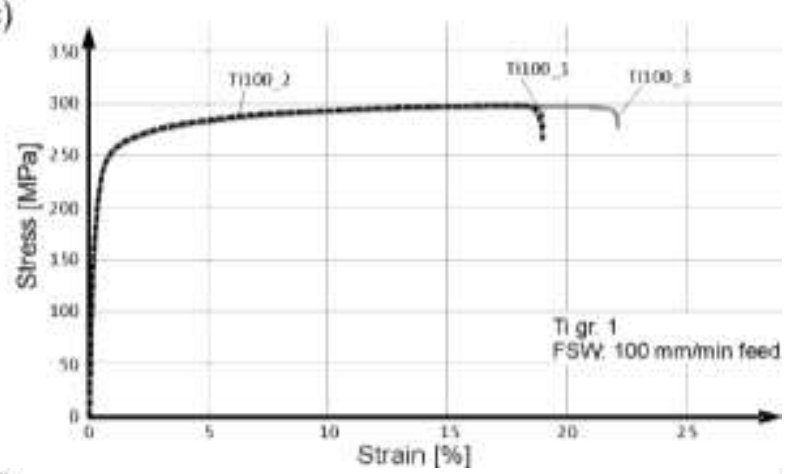

d)

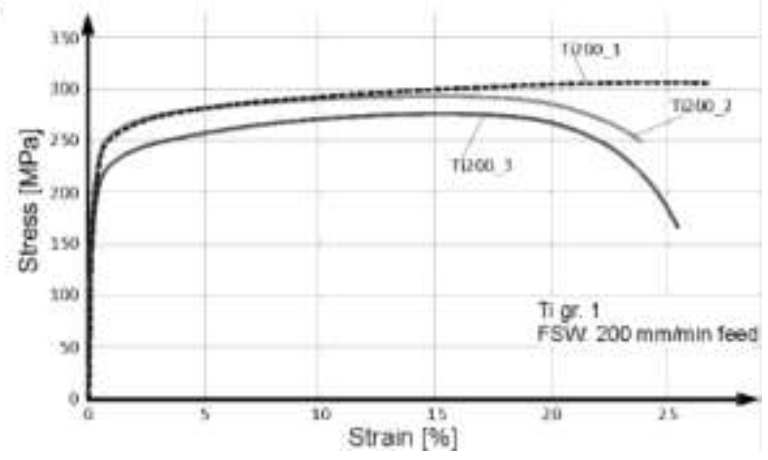

Figure 4. Stress-strain curves obtained during tensile tests performer on Ti gr. 1 base material (a) and samples with FSW joints produced under different feeds

(b, and

d) 
Table 2. Strength properties of Ti gr. 1 and FSW joints.

\begin{tabular}{|c|c|c|c|c|}
\hline & BM & Ti-75 & Ti-100 & Ti-200 \\
\hline $\begin{array}{c}\mathrm{E} \\
{[\mathrm{MPa}]}\end{array}$ & $1.1010^{5}$ & $0.9110^{5}$ & $0.9510^{5}$ & $0.9310^{5}$ \\
\hline $\begin{array}{c}\mathrm{R}_{0,2} \\
{[\mathrm{MPa}]}\end{array}$ & 266.8 & 214.5 & 221.7 & 215.3 \\
\hline $\begin{array}{c}\mathrm{R}_{\mathrm{m}} \\
{[\mathrm{MPa}]}\end{array}$ & 317.7 & 295.8 & 299.5 & 293.7 \\
\hline $\mathrm{A}_{50}[\%]$ & 23.3 & 23.3 & 19.7 & 24.9 \\
\hline
\end{tabular}

It can be noticed the results obtained for base material and Ti-100 series are repeatable without more significant variations contrary to $\mathrm{Ti}-75$ and $\mathrm{Ti}-200$ series where every time one result is peculiar. Young's modulus E determined for FSW samples is $15-19 \%$ lower in comparison to base material what is influenced. In each case of joints yield strength $\mathrm{R}_{0,2}$ and ultimate strength $\mathrm{Rm}$ are similar and lower than obtained for base material. On the other hand, the values of elongation for Ti-100 series are the lowest what means that these joints are more brittle compared to others and for Ti-200 series the elongation is the highest. Compared to the base material curves, the obtained joints have higher strain hardening coefficient.

\subsection{Microhardness}

It has been reported that significant grain refinement occurring in the stir zone causes the increasing of microhardness in this area up to the value of 180-200 HV0,1. The peak hardness always occurs in the stir zone and then gradually decreases across thermo-mechanically affected zone. The obtained microhardness values show a wide spread through cross-section of samples, what indicates on nonhomogeneous hardening of material in the friction stir welding process. The peak hardness of investigated samples decreases with the increasing of welding velocity.

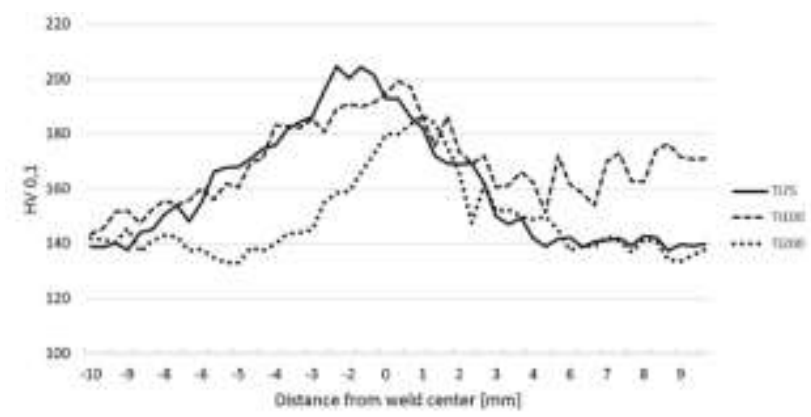

Figure 5. The results of the microhardness analysis.

\section{Discussion}

The friction stir welding of titanium grade 1 has a significant impact on its microstructure. Welding process creates the stir zone (SZ), characterized by ultrafine dynamically recrystallized grain microstructure and thermo-mechanically affected zone (TMAZ) consists of plastically deformed grains not affected by dynamic recrystallization phenomenon. In all samples has been reported the occurring of ultrafine SZ microstructure with grain size about $5 \mathrm{~m}$. What is important, the peak temperature in friction stir welding process of titanium can exceeds the temperature of its allotropic transformation what can lead to formation of serrated grain boundaries in the stir zone, as the result of the $\beta \rightarrow$ $\alpha$ transformation during cooling stage after formation of joint $[11,19]$. On the other hand, the allotropic transformation $\alpha \rightarrow \beta$, occurring in the heating stage of friction stir welding process and promoted by severe plastic deformation in the stir zone causes the dynamic restoration in this area [20,21]. No occurrence of serrated grain boundaries has been noticed in the stir zone, what suggest that the peak temperature during welding did not exceed the allotropic transformation temperature $\left(882^{\circ} \mathrm{C}\right)$. The ultrafine grain structure of stir zone results in the hardening of material, what finds its confirmation in the results of microhardness analysis. The increasing of microhardness in the stir zone compared to the base material is equal to $65 \mathrm{HV} 0,1,60 \mathrm{HV} 0,1$ and $45 \mathrm{HV} 0,1$ for welding velocities $75 \mathrm{~mm} / \mathrm{min}, 100 \mathrm{~mm} / \mathrm{min}$ and $200 \mathrm{~mm} / \mathrm{min}$ respectively. Despite of used welding velocity the width of the stir zone is equal to $5.5 \mathrm{~mm}$ at the half of its height. The grain size of thermomechanically affected zone microstructure slightly grows along with move from stir zone to base material (BM). That fact, together with observation of twin grain boundaries in the area closer to BM shows incomplete transformation of plastically defected grain microstructure by recrystallization process. Deformation texture of this zone reflects the material flow around the tool during welding process. In comparison to friction stir welding of aluminium alloys, in which the TMAZ is far wider, the titanium has significantly higher recrystallization rate, what results in formation of relatively thinner zone [22]. The microstructure observation together with results of microhardness analysis shows the relation between thickness of TMAZ and the used welding velocities. Together with increasing in welding velocity the TMAZ decreasing, what relates to the longer time of acting of the welding tool on the workpiece material. At the same time, the microhardness analysis results do not show occurrence of heat affected zone (HAZ) in the researched samples. In case of aluminium alloys, the HAZ can be characterized by local decrease in microhardness below the BM value. Softening of joint in this zone is causes by grain growth of undeformed material. The reason of HAZ absence in the titanium joints compared to the aluminium results from the lower thermal conductivity of titanium, as well as, its higher melting point, which determines the temperature of grain growth $[23,24]$. In the performed FSW joints, the two kinds of defects occurrence have been stated. On the bottom of joints cross-section the kissing bond defects is present. According to research, this imperfection is induced by insufficient degree of the stirring to breaking up the initial oxide layer on the joining surface $[25,26]$. The formation of kissing bond in this investigation could be caused by difference between the joined sheet thickness $(3.2 \mathrm{~mm})$ and pin's length (3 $\mathrm{mm}$ ), what can lead to the lack of penetration and the ineffective stirring degree on the bottom of workpiece. 
The second kind of defect present in performed joints is the tunnelling defect, which can be caused by both the improper welding parameters and the inappropriate welding tool shape. Considering the fact that this defect occurs in all three joints, regardless of used welding velocity, as the reason of improper material flow during welding process. Despite the imperfections the obtained joints exhibit very good mechanical properties. The average joint efficiency is equal to $93.1 \%, 94.3 \%$ and $92.4 \%$ for the samples Ti-75, Ti-100 and Ti-200 respectively. It is important to mention that the thickness of welded plates was about $3.2 \mathrm{~mm}$ and it had to be reduced to $3 \mathrm{~mm}$ by milling during the preparation of tensile test samples. This operation resulted in decreasing of the kissing bond defect's impact on the mechanical properties of tested joints. The results of tensile test indicate on almost negligible impact of tunnelling defect on the static mechanical properties of joints, what is an unusual issue. Good tensile strength of friction stir welded titanium is related to ultrafine grain microstructure, which occurs in the stir zone. On the other hand, no softening of material has been noticed in the thermo-mechanically affected zone. In all cases the yield strength of welded samples was lower than base material by about $40 \mathrm{MPa}$. It is worth noting that the welding process did not decrease the ductility of titanium grade 1 in most cases. It has been reported that Young's modulus of welded samples is $15-19 \%$ lower in comparison to the base material. This result can be explained by ultrafine grain structure of stir zone, as well as, the tunnelling defect, which has reduced slightly the real cross-section area of the tested samples.

\section{Conclusions}

In this study the Titanium Grade 1 sheets with $3.2 \mathrm{~mm}$ in thickness have been welded by friction stir welding technique using different welding velocities and the tool made of W25Re. The microstructure, microhardness and mechanical properties of obtained joints have been investigated. It has been stated that despite the presence of weld imperfections, the tested joints exhibit a very good joint efficiency above $90 \%$ thanks to dynamically recrystallized ultrafine grain microstructure of the stir zone.

\section{Acknowledgements}

This work was supported by the university grant RMN $725 / 2017$.

\section{References}

1. C. Veiga, J. Davim, A. Loureiro, Reviews on Advanced Materials Science 32, 133-148 (2012)

2. C. Leyens, M. Peters, Titanium and Titanium Alloys: Fundamentals and Applications (2003)

3. M. Peters, J. Kumpfert, C.H. Ward, C. Leyens, Advanced Engineering Materials 5, 419 - 427 (2003)
4. H.-X Jin, K.-X Wei, J.-M Li, J.-Y Zhou, W.-J. Peng, Zhongguo Youse Jinshu Xuebao/Chinese Journal of Nonferrous Metals 25, 280-292 (2015)

5. E. Uhlmann, R. Kersting, T. Klein, \& M. Fernando Cruz, A. Borille, Procedia CIRP 35, 55-60 (2015)

6. M. Gurevich, Problems of the welding of titanium and its alloys (1970)

7. Y.M. Ahmed, K. Salleh, K. Sahari, M. Ishak, Welding of Titanium (Ti-6Al-4V) Alloys: A Review (2012)

8. K. Jata, P.R. Subramanian, A.P. Reynolds, T. Trapp, E. Helder, Proceedings of the International Offshore and Polar Engineering Conference, 22-27 (2004)

9. R. S. Mishra, M. W. Mahoney, Friction Stir Welding and Processing, ASM International (2007)

10. M. J. Russell, 10th World Conference on Titanium, (2003)

11. J.-D. Kim, E.-G. Jin, S. Murugan, Y.-D. Park, Journal of Welding and Joining 35, 6-15 (2017)

12. N. Xu, Q. Song, Y. Bao, Y. Jiang, J. Shen, X. Cao, Science and Technology of Welding and Joining 22, 610-616 (2017)

13. G. Buffa, L. Fratini, F. Micari, L. Settineri, Transactions of the North American Manufacturing Research Institution of SME 40, 785-794 (2012)

14. Q. Liu, R. Steel, J. Peterson, S. Horman, M. Collier, D.B. Marshall, J.B. Davis, M. Mahoney, Proceedings of the International Offshore and Polar Engineering Conference 4, 298-302 (2010)

15. B. Thompson, TMS Annual Meeting, 105 - 112 (2011)

16. G. Buffa, L. Fratini, F. Micari, L. Settineri, Transactions of the North American Manufacturing Research Institution of SME 40, 785-794 (2012)

17. Y. Zhang, Y. S. Sato, H. Kokawa, C. P. Hwan Seung. S. Hirano, Materials Science and Engineering: A 488, 25-30 (2008)

18. U. Sobczak, M. Wachowski, L. Śnieżek, M. Bajkowski, K. Gocman, Machine Dynamics Research 41, 53-64 (2018)

19. K. Gangwar, M. Ramulu, Materials \& Design 141 (2017)

20. G. Buffa, A. Ducato, L. Fratini, Materials Science and Engineering: A 581, 56-65 (2013)

21. Y.F. Sun, H. Fujii, Materials Science and Engineering: A 527, 6879-6886 (2010)

22. G. Çam, S. Mistikoglu, Journal of Materials Engineering and Performance 23 (2014)

23. H. Fujii, H. Kato, K. Nakata, K. Nogi, Ceramic Transactions 198, 51 - 56 (2011)

24. P. Podržaj, B. Jerman, D. Klobčar, Metalurgija 54, 387-389 (2015)

25. N. Khan, A. Siddiquee, Z. Khan, S. Shihab, Journal of Alloys and Compounds 648 (2015)

26. K. P. Mehta, V. J. Badheka, Procedia Technology 23, 513-518 (2016) 